\title{
Analysis of the impact of an operator's workstation on the safety of functioning of selected road transport systems
}

Łukasz Muślewski ${ }^{1}$,

${ }^{1}$ University of Science and Technology in Bydgoszcz, Faculty of Mechanical Engineering, Al. prof.

S. Kaliskiego 7, 85-796 Bydgoszcz, Poland

\begin{abstract}
Modern times are characterized by fast economic and social development. However, not all spheres of life have developed in a sustainable manner, for example some elements of anthropotechnical systems are still far from being sustainable. This results in low safety level of these systems involving high risk of injury or death caused by road accidents. Transport systems of the type Human-Machine-Environment $<\mathrm{H}-\mathrm{M}-\mathrm{E}>$, where undesired events are caused by human behavior, belong to such systems. The author of this study has addressed the issues connected with the impact of man-made objects on their operation safety. The objects in question are selected transport systems and the study subject is assessment of the equipment operator's behavior. The main goal of this study is to provide assessment and analysis of the impact of transport means ergonomics on the quality of transport services they provide. The research object are delivery trucks with the maximum vehicle weight up to 3.5t. The first part of the study contains identification of the factors and threats which affect functioning of transport systems. Further, ergonomics criterion is defined and the factors affecting ergonomics of selected transport means are provided. A questionnaire survey was performed with participation of professional drivers who were asked to identify the factors which have an adverse effect on the safety of the transport process as well as factors that increase the drivers' comfort of work. Basing on this, an analysis of the results was performed and negative aspects involved in driving ergonomics were identified.
\end{abstract}

\section{Introduction}

The problems connected with the safety of transport systems is an interdisciplinary issue and applies to transport psychology, theory of systems, ergonomics, transport, maintenance and others $[1,2]$.

Socio-technical systems $\langle\mathrm{H}-\mathrm{T}-\mathrm{E}\rangle$, including transport ones, are characterized by similar features regardless of the industry they are used in. The level of their safety is affected by the operator's behavior (human factor), the technical object (transport means) and the impact of the environment. It needs to be highlighted, though, that it is the human factor that is considered to have the highest influence on a transport system functioning safety[3,4].

The concept of factor, that is, a quantity being its theoretical image, is one of the notions of the science idealizing concepts [5]. Hence, a factor can be interpreted in the mathematical form defining its relations. Human factor as an element affecting a system is a special case of a factor. According to work [6], the concept of human factor is a design and engineering of the human-machine-environment systems to improve people's

\footnotetext{
* Corresponding author: Lukasz.Muslewski@utp.edu.pl
} 
behaviors. The concept of 'human factors' is often referred to as a scientific discipline like ergonomics. Study [7] provides an analysis of the human factor concept, thus for the needs of this study, a definition was accepted which assumes that a human factor is a general term commonly used as a name of a specialized discipline which deals with the relations between a man an a machine. It focuses on the problems of perception, psycho-physics, decision making and other aspects involved in the information processing. Sometimes it applies to such elements as: equipment, physical environment, tasks and persons who perform the work [8-10]. A system "human - machine" is a relatively closed system, i.e. the processes involved in the system operation are of cyclic character and always return to the initial point which does not rule out entrances into it and exits from it including cooperation with the environment [11]. The human factor is often identified with a human, however, such simplification does not provide a full picture of the human impact as it should always be considered in a situational contexts which affect human reactions and predispositions such as: temperament, aggression, feeling of control etc. [7].

The design process involves integrating technical structures with humans into one biotechnical system 'human - to - environment". Therefore, all machines need to be equipped with specially constructed workstations for the operators in order to provide the system with safe operation. If it comes to transport means operation systems, this is the machine operator who is usually responsible for collisions and accidents [12]. A respective directive includes major requirements regarding safety and health protection in relation to all machines [13].

\section{Identification of the factors affecting safety of transport system operation}

Providing technical systems with high safety level is a problem tha occurs in many branches of the national economy. Road traffic transport system are socio-technical systems which need to be provided with ensuring high safety level because their operation is largely affected by people who are operators of technical objects, passengers of transport means and road traffic participants (bikers, side walkers, others) [14].

The concept of transport safety is understood as the system ability to operate in a given environments with no accidents or undesired road events. In work [15] the authors conclude that the science regarding safety, also referred to as safety engineering, addresses the methods for loss prevention which can be used for verification of the system safety control decisions, basing on the results of socio-technical models tests. An operation system can be considered rational only when it contributes to, optimal in terms of accepted criteria, most often economic, achievement of set goals. [16]

The below listed environmental factors have an influence on a driver's behavior in the road environment[17]:

- other vehicles that make driving more difficult,

- pedestrians on the pavements who distract attention,

- pedestrians entering the road,

- bikers on the road,

- dangerous behavior of other drivers,

- animals near the road,

- time of waiting in line to enter an intersection,

- standing in a traffic jam,

- frequent stops in front of traffic lights,

- bumps in the road,

- water, mud, snow,

- slippery surface,

- weather, climate, 
- ads in the road proximity, shop displays,

- insufficient road lighting,

- blinding by the sunlight or other vehicles,

- invisible horizontal signs,

- poor visibility of the road, vertical signs and traffic lights,

- confusing road traffic rules,

- to many signs and too much information,

- unclear marked intersection.

According to the author [17], the features of the road environment have a significant impact on the safety margin to be accepted by the drivers, hence, on the number of road traffic victims.

According to the authors of work [18], the factors affecting safe driving can be divided according to four criteria due to:

- external environment of the vehicle:

- quality of roads and their marking,

- atmospheric conditions,

- road traffic volume,

- time - day/night,

- workstation:

-workstation ergonomics,

- physical factors, i.e. noise, vibrations, temperature,

- technical state of the vehicle,

- the driver:

- psycho-physical fitness,

- personality traits,

- age and experience,

- fatigue and sleep deficit,

- health condition,

-work organization:

- length of distance to cover,

- time of travel,

- stops to relax.

All these factors have an influence on the driver's behavior which affects safety of the passengers and cargo and can pose a threat to lives of the passengers, other road users and their own. The driver's behavior and actions can be divided into three categories [19]:

- logic,

-illogic,

- irrational.

The behavior of drivers is affected by emotional processes, character traits, temperament, motivation, attitudes which is closely related to the driver's age and his/her job experience. Psychological aspects of the driver's personality include [19]:

- thinking,

- memory,

- perception,

- attention.

Physiological predispositions of drivers including vision, hearing, responsiveness, reaction time, alertness, drowsiness and fatigue which depend on the age and gender play a very important role in driving as well [15, 17, 19]. The authors of work [4] have analyzed the impact of ergonomic risk and muscle-spine related ailments which accompany a driver of a passenger car while driving and have indicated which health problems may occur. 
In its further part, the study deals with the problems of ergonomics of different types of vehicles which is a significant criterion for assessment of transport systems functioning safety.

\section{Analysis of the problems connected with drivers' workstation ergonomics}

The name ergonomics comes from Greek. Ergon work and nomos natural laws. Ergonomics is a science which combines human psycho-physical abilities with operation of machines and devices [20].

Ergonomics is referred to as an applied science. It focuses on human needs when designing transport means to make them adjusted to the operator and the passengers [21].

The beginnings of the concept of ergonomics date back to the period of creation of the first tools. Homo habilis that is, a skillful man, was probably the first to pay attention to the aspect of ergonomics while creating new tools. After the II world war, ergonomics developed to provide safe working conditions. It aimed at optimizing maximum muscle loads and force values to be used by a worker to do his/her job [22].

Ergonomic aims at adjusting tools, machines and devices to the physical and psychical needs of the man. It focuses on the human needs rather than the economic effect [4, 23].

The major assumption of ergonomics is to provide solutions that are most effective in terms of economy and ecology and are involved in job efficiency, comfort and safety improvement [7].

Ergonomics refers to such scientific disciplines as: anthropology (deals with measurements of human body to be used in creation of a workstation), work physiology (assessment of phenomena that occur in work in order to prevent fatigue and tiredness), occupational safety and health (prevents factors that cause diseases),work psychology (addresses two aspects: adaptation of a human to work, adjustment of work to a human , and adaptation of a human to other humans) [24, 25, 26].

Analyzing the factors conditioning drivers' job it needs to be emphasized that they involve many aspects affecting their health which in turn has an impact on accomplishment of transport tasks. In their daily work the drivers have to face the internal and external factors which directly affect their behaviors in the road traffic environment [1].

\section{Ergonomics of selected transport means}

In view of the above, it needs to be highlighted that ergonomics of a driver's workstation is one of the factors that have a significant impact on the transport means operators' work quality which translates directly into safety of transport services to be provided by them.

\subsection{Survey}

The study includes the results of a survey on the subject of workstation economics for drivers of delivery trucks up to $3.5 \mathrm{t}$.

The survey was carried out for a group of professional drivers, classified in terms of age, gender, driving license class and the age of their vehicles. Persons who were employed in transport companies as users of vehicles were statistical units of the survey. The surveyed group included 50 respondents. The survey subject was the vehicle ergonomics and the main goal of the survey was assessment of ergonomic conditions while driving the vehicle. The survey consisted of seven questions, both open and closed ones. Each questionnaire was marked from 1-50.

The analyzed group of respondents included 45 men and 5 women. The age of fifteen respondents was 41-50, twenty of them were (31-40), 8 were more than 50 years old and seven from $21-30$. It needs to be noted that those younger than 21 were not included in the survey. In terms of job experience the respondents were divided into groups according to 
the period of employment. Most of the respondents had been employed for more than 5 years (35), 7 for 3-5 years, 6 for 1-3 years, whereas 2 shorter than for one year. The next aspect taken into account was the vehicle used by the respondents. They were divided into two types: up to do $3.5 \mathrm{t}$, with no trailer and with a trailer. The first group included 39 vehicles, whereas, the second 11 vehicles. The last division criterion of the respondents was the age of their vehicles. It consisted of five time periods. Most drivers (16) used vehicles manufactured in (2006- 2010), 19 used trucks manufactured after 2010, 9 between (20012005), 5 vehicles from (1995-2001), one driver used a vehicle manufactured before 1995. The survey questions are presented in table 1.

Table 1. The survey questions.

\begin{tabular}{|c|c|}
\hline No. & Question \\
\hline 1. & $\begin{array}{l}\text { What is your opinion about the comfort of driving according to grading scale from 1(poor) } \\
\text { to } 5 \text { (excellent)? }\end{array}$ \\
\hline 2. & $\begin{array}{l}\text { Which element of the drover's cabin needs to be changed or modified and why (seat, } \\
\text { steering wheel, gear change system, windshield mirrors, safety belts, pole, armrest, } \\
\text { soundsystem others )? }\end{array}$ \\
\hline 3. & $\begin{array}{c}\text { Provide the assessment of difficulty in operation of the cabin equipment } 1 \text { (low) }-5 \text { high) and } \\
\text { list the devices which you find most difficult to operate? }\end{array}$ \\
\hline 4. & $\begin{array}{l}\text { Which of the external factors and to what degree is the most annoying for you while } \\
\text { driving the vehicle, use scale from } 1 \text { (the least ) to } 5 \text { (the most) (noise, precipitations, } \\
\text { slippery road surface, limited visibility, traffic jams temperature, other road users)? }\end{array}$ \\
\hline 5. & $\begin{array}{l}\text { Which devices and to what degree according to the scale } 1 \text { (the least ) -5 (the most), } \\
\text { make ypur work more enjoyable (fridge, television, roof-window, navigation, multi- } \\
\text { functional steering wheel, air conditioning webasto, gas cooker, others)? }\end{array}$ \\
\hline 6. & $\begin{array}{l}\text { Which activity/manouver is difficult for you due tothe vehicle structure and/or } \\
\text { equipment (parking, loading/unloading, compulsory standby, driving)? }\end{array}$ \\
\hline 7. & $\begin{array}{l}\text { Is it possible to improve ergonomics of your vehicle from the point of view of the } \\
\text { operator? }\end{array}$ \\
\hline
\end{tabular}

\subsection{Survey results and their analysis}

On the basis of the survey results carried out for a group of fifty delivery van drivers, the basic statistical indexes were determined for the obtained scores, which are presented in table 2 .

Table 2. Mean values of the survey scores.

\begin{tabular}{|c|c|c|c|c|c|c|c|}
\hline \multicolumn{8}{|c|}{ Questions } \\
\hline & 1 & 2 & 3 & 4 & 5 & 6 & 7 \\
\hline Sum & 177.5 & 209 & 182.5 & 187.3 & 59.66 & 188.8 & 205 \\
\hline Average & 3.55 & 4.18 & 3.65 & 3.75 & 1.19 & 3.78 & 4.10 \\
\hline Median & 3.75 & 4.50 & 3.75 & 4.29 & 1.06 & 3.75 & 5.00 \\
\hline Stand-dev & 0.99 & 0.55 & 1.40 & 0.96 & 0.89 & 0.31 & 1.94 \\
\hline Coef-Var & 0.01 & 0.003 & 0.01 & 0.01 & 0.01 & 0.002 & 0.01 \\
\hline Min & 1.25 & 2.5 & 1.25 & 2.43 & 0.00 & 2.5 & 0 \\
\hline Max & 5 & 5 & 5 & 4.57 & 3.89 & 5 & 5 \\
\hline
\end{tabular}

An analysis of the answers to the first question shows that it was given the two highest grades by the biggest number of the respondents. Hence, it can be said that a great majority of the drivers are satisfied with the comfort of driving their vehicles.

Number 2 was supposed to find out which element of the cabin equipment needs to be changed or modernized. Almost $50 \%$ of the respondents indicated the driver's seat. They 
claimed that: it is not comfortable, it often breaks down, its adjustment system is poor, is badly profiled, long driving causes pain in lumbar vertebra, there should be hydraulic adjustment, the foam inside the seat is of poor quality, a longer trip results in spine pain, head rests are not of sufficient quality, the seat should be better matched to the body. The second elements which was indicated by the drivers as not good enough were mirrors. They indicated that the mirrors: limit visibility, are not heated, generate the so called "blind spot", they should be larger, their shoulders are too short, should be electrically controlled and they provide too small field of view. The next problem that was indicated by the respondents was the system od gear change and the type of gear lever 'A', which was mentioned by eight persons for each issue. Another element which was indicated by 7 respondents was the steering wheel. The drivers claimed that the steering wheel should be multi-functional and made of leather. As far as safety belts are concerned the respondents said that: they should be more elastic, they often get blocked and are too tight and 'pull'. Two drivers indicated the arm rest as an element that needs to be modernized because: it is too stiff, and there should be two armrests on both sides. The windshield has some characteristics which undoubtedly disturb the drivers in their work. These are: poor visibility, generating frost or steam as well as the fact that the wipers do not cover the whole surface of the windshield. The drivers had also objections concerning the sound system and loudspeakers and their configuration which in their opinion needed modification.

The third question consisted of two parts. The first part was about the level of difficulty in operation of the devices inside the driver's cabin and it turned out out that the drivers did not find it difficult to operate the cabin equipment, whereas 9 respondents had some difficulties in operation of the tachometer, use of navigation, reading the deck computer announcements, operation of the radio and temperature programmer.

A multiple choice question number 4 was connected with the most annoying external factors. Most respondents indicated the infrastructure and traffic jams (including congestions) as the most irritating factors. It is commonly known that traffic congestions occur in many towns particularly during rush hours. They are very disturbing due to the pressure of delivery time. Other annoying elements include: noise, precipitation and slippery road surface.

The fifth question was about the most useful devices fixed in the cabin such as: fridge, navigation, webasto, television, multi-functional steering wheel, gas cooker, window roof, air conditioning or others. According to the respondents the most useful devices are navigation and air conditioning. Television scored the least points. The respondents found navigation and air conditioning to be indispensable for driving as navigation significantly supports driving and air conditioning significantly increases the comfort of work.

The sixth question was about difficulties in activities involved in their job. Respondents chose a specific activity and gave reasons why it poses the most problems. Most respondents indicated loading and unloading to be the most disturbing activity, whereas, according to them, the least disturbing was driving itself. In their opinion loading and unloading take most time, there are not enough tapping points, the loading should be mechanical, some companies take drivers for persons responsible for loading and unloading the truck, besides they have to wait for too long and there are no side doors to enable unloading on the side or there is no special platform to be used for loading/unloading. Parking was chosen to be problematic as well because of: lack of parking sensors, lack of cameras, fear of damage or accident due to the vehicle large size and high length, or little parking space or limited visibility.

Question 7 was about the vehicle ergonomics improvement. The drivers could propose their own solutions to improve the work quality and efficiency. 39 respondents said that it was not possible to improve ergonomics in their vehicles, however, the other respondents 
proposed some solutions including: modification of the suspension, increasing the engine power, increasing visibility, montage of air conditioning, replacement of the standard steering wheel with a multifunctional one, automatic gear box, improvement of the driver's seat, reduction of noise and creation of more lockers.

Additionally, in order to check correlation between particular questions the correlation coefficient significance test was performed on the basis of the survey results. Since the population of the sample was $n=50$, hence it is statistically significant for the variables from the continuous distribution. Based on an analysis of the results it was found that only four pairs of variables have significant correlations in relation to each other, whereas their significance level is expressed by low values. It provides the basis to state that this set is not redundant.

\section{Conclusions}

Transport systems are specific types of socio-technical systems where more than $90 \%$ of the undesirable events are caused by fault of the human. The decisions of a vehicle operator, that is a driver, which are frequently affected by the ergonomic factors, have a significant impact on the vehicle. Many of these factors influence the driver's behavior which in case of fast reaction can lead to a collision or an accident. To provide appropriate assessment of the operator's behavior in a situation of a higher risk it is necessary to investigate the impact of the vehicle ergonomic conditions.

This study provides an analysis of an operator's - a supply truck driver's workstation ergonomics. A survey was used to identify factors that have an adverse effect on the quality of the transport process. The impact of selected internal and external factors on drivers' work ergonomics was assessed. The problems and factors which could contribute to ergonomic improvement in the transport means they use have been analyzed. A statistical analysis and the correlation coefficient significance test was made as well. As the level of the correlation significance value was particular questions are disjoint and do not reflect the information which is included in the other questions. There is a need to conduct further research on this subject and compare the results. The group of passenger car or supply trucks with more than 3.5t.capacity drivers or drivers of other transport means should be surveyed as well to better match the machines and devices with their operators' physical and psychological traits.

\section{References}

1. Ł. Muślewski, B. Landowski, N. Mackiewicz, M. Pająk, Research and analysis of work ergonomics of selected transport means operators. International Automotive Conference, Materials Science and Engineering, 1757-8981, (2018)

2. M. Pająk, Ł. Muślewski, B. Landowski, A. Grządziela, Fuzzy identification of the reliability state of the mine detecting ship propulsion system. Polish Maritime Research 1(101) Vol.26, 55-64 (2019)

3. D. Koradecka (red), Occupational safety and health, (CIOP - PIB, Warszawa 2008)

4. R. Makarowski, Risk and stress in sports aviation, (Difin Warszawa 2010)

5. Transport Research Laboratory, Construction logistics and cyclist safety, Technical report (2012)

6. P.G. Dempsey, M.S. Wogalter, P.A. Hancock, What's in a name? Using terms from definitions to examine the fundamental foundation of human factors and ergonomics science (2000)

7. Ł. Muślewski, Evaluation method of transport systems operation quality. Polish Journal of Environmental Studies. Vol. 18, No. 2A (2009)

8. D. Starkowski, K. Bieńczak, W. Zwierzycki, Carv transport in Poland and abroad. Compendium of practical knowledge. Vol III. Driver's work environment. 
9. T. Kałaczyński, M. Łukasiewicz, J. Musiał, R. Polasik, M. Szczutkowski, N. Dluhunovych, J. Wilczarska, T. Kasprowicz, Analysis of the diagnostic potential research thermovision in the technical state of combustion engine injectors assessment, Engineering Mechanics, 1805-8248 (2018)

10. M. Styp-Rekowski, E. Mańka, M. Matuszewski, M. Madej, D. Ozimina, Tribological problems in shaft hoist ropes wear process. Industrial Lubrication and Tribology, Vol. 67, pp. $47 \div 51$ (2015)

11. R. Krystek (red), Integrated transport safety system, vol. I, (WKiŁ 2009)

12. Transport Research Laboratory, Construction logistics and cyclist safety, Technical report (2012)

13. Directive 206/42/WE European Parliament and Council of 17 May 2006 on unification of regulations concerning machines, altering directive 95/16/WE. OJ L 157, 26 (2006)

14. M. Balke, R. Karpiński, Road accidents due to technical reasons in statistical terms based on international and national research, Logistyka 3 (2014)

15. M. Gerigk, Formal method for safety assessment of damaged ships on the basis of analysis of causes and effects of accidents. XXXIII Winter School of Reliability

16. J.L. Frąckiewicz, Efficient operation, (Wrocław 1980)

17. B. Tuchańska, Idealization and discovery. Factor and quantity, [w:] Discovery, truth, abstraction, empiricism, history and a idealization. A. Klawiter, L. Nowak (red.), (PWN Warszawa 1979)

18. T. Szczuraszek, Urban traffic safety, (Editorial Office of Transport and Communication. Warszawa 2008)

19. J. Wicher, Safety of road traffic and cars, (Editorial Office of Transport and Communication. Issue 2, Warszawa 2004)

20. R. Madhusudana, J. Reson J, Products of Sets: Ordered and Unordered Resonance 21 pp 557-64 (2016)

21. D. Bąk - Gajda, J. Bąk, Psychology of transport and road traffic safety, (Difin, Warszawa 2010)

22. D. Meadows, Thinking in Systems (White River Junction, Chelsea Green Publishing 2008)

23. J. Musiał, Ł. Muślewski, M. Pająk, A. Grządziela, Analysis of vibration time histories in the time domain for propulsion systems of minesweepers. Journal of Vibroengineering 17, 3, 1309-1316 (2015)

24. G. Dahlke, J. Kamczyc, R. Rakowski, Diagnostics and assessment of passenger car cabin ergonomics i ocena ergonomiczności, Logistic 3 (2014)

25. M Łukasiewicz, T Kałaczyński, J. Musiał, J. Shalapko, Diagnostics of buggy vehicle transmission gearbox technical state based on modal vibrations, Journal of Vibroengineering 16, 6, 3137-3145 (2014)

26. M. Matuszewski, T. Mikołajczyk, D. Yu. Pimenov, M. Styp-Rekowski, Influence of structure isotropy of machined surface on the wear process International Journal of Advanced Manufacturing Technology: Vol. 88, Iss. 9, pp. $2477 \div 2483(2017)$ 